\title{
IDENTIFIKASI KOPI BUBUK BERDASAR BAHAN CAMPURAN MENGGUNAKAN SENSOR GAS DAN METODE JARINGAN SYARAF TIRUAN LEARNING VECTOR QUANTIZATION
}

\author{
M. Amirul Prihatama $P^{1)}$,,Misbah ${ }^{2)}$, Yoedo Ageng Suryo ${ }^{3)}$ \\ 1,2,3) Jurusan Teknik Elektro, Fakultas Teknik, Universitas Muhammadiyah Gresik \\ 1) amirulprihatama@gmail.com, ${ }^{2)}$ misbah@umg.ac.id, ${ }^{3)}$ mryoedo@ gmail.com \\ J1. Sumatra No 101, Gresik 61121, Jawa Timur, Indonesia
}

\begin{abstract}
ABSTRAK
Era globalisasi sekarang ini konsumsi kopi dalam kehidupan sehari-hari terlihat sangat wajar. Dari situlah ada beberapa oknum penjual kopi atau produsen kopi bubuk yang dengan sengaja mencampur dengan beberapa bahan tersebut untuk mendapatkan keuntungan lebih banyak.Pada penelitian ini akan dibahas suatu alat dan sistem identifkasi bau dengan metode JST (Jaringan Saraf Tiruan ) LVQ yang diharapkan dapat mendeteksi keaslian komposisi dan jenis campuran kopi yang dijual dipasaran. Hasil pembuatan alat dan sistem identifkasi bau dengan metode JST (Jaringan Saraf Tiruan ) LVQ didapatkan hasil bahwa JST mampu untuk mengidentifikasi dan membedakan antara kopi asli, kopi jagung, kopi beras dan kopi kedelai dengan tingkat keakuratan 95,92\% dan tingkat eror $4,08 \%$.
\end{abstract}

Kata kunci : sensor gas, bubuk kopi asli, JST

\section{PENDAHULUAN}

Kopi (Coffea sp.) adalah spesies tanaman yang termasuk dalam famili Rubiaceae dan genus Coffea. Tanaman kopi terdiri dari jenis Coffea robusta, Coffea arabica, dan Coffea liberica. Kopi merupakan komoditas ekspor dunia dengan nilai ekonomis yang relatif tinggi di pasaran, Indonesia kopi juga merupakan salah satu komoditas ekspor unggulan yang terus dikembangkan [11][15]. Nilai ekonomis yang tinggi tersebut, saat ini selain bubuk kopi asli yang dijual di pasaran terdapat juga bubuk kopi campuran yang didalamnnya ada macam-macam campuran yang ditambahkan ke dalam bubuk kopi asli untuk mendapatkan sensasi atau rasa yang baru Disamping itu adanya kopi campuran bercampur biji kedelai dikhawatirkan akan menimbulkan gejala pada orang yang alergi dengan kedelai. Penelitian yang serupa menggunakan sensor gas sebatas pada mengidentifikasi jenis bubuk kopi arabika dan kopi robusta dan metode JST Backpropagation.[12]. Berdasarkan kasus dan data diatas, penelitian ini diharapkan dapat melengkapi data riset yang sudah ada. agar dapat melengkapi data riset yang sudah ada. Keperluan komponen elektrik yang dibutuhkan sistem ini antaralain Mikrokontroler Arduino Uno, LCD 16 x 2, Power Suplly (AC-DC) 12V;3A, Sensor DHT-11, dan empat jenis sensor gas yaitu MQ-2, MQ-7, MQ-136 dan MQ-137. Pertimbangan pemilihan keempat jenis sensor gas diatas berkaitan dengan pendeteksian gas $\mathrm{SO}_{2}, \mathrm{CH}_{4}, \mathrm{CO}$ dan $\mathrm{NO}_{2}$. Gambar 11 menunjukkan salah satu penampang sensor gas yang digunakan

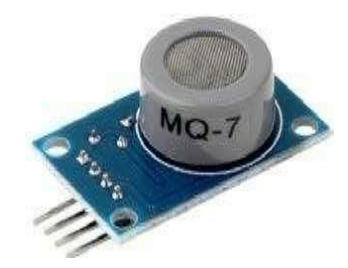

Gambar 1.1. Sensor Gas MQ-7 
Volume 15 Nomor 2 (2020) 11-15

E-Link P-ISSN 1858-2109 E-ISSN 2656-5676

Jurnal Teknik Elektro dan Informatika

\section{METODOLOGI PENELITIAN}

Metode penelitian yang digunakan pada penelitian berisi tentang cara perancangan prototipe, perancangan aplikasi, dan implementasi sistem.

\subsection{Pembuatan Sistem}

Pembuatan sistem meliputi pembuatan hardware dan software . Agar lebih memahami kinerja pada sistem ini maka dibuat skema kerja keseluruhan sistem ini ditunjukkan pada gambar 2.1. berikut ini

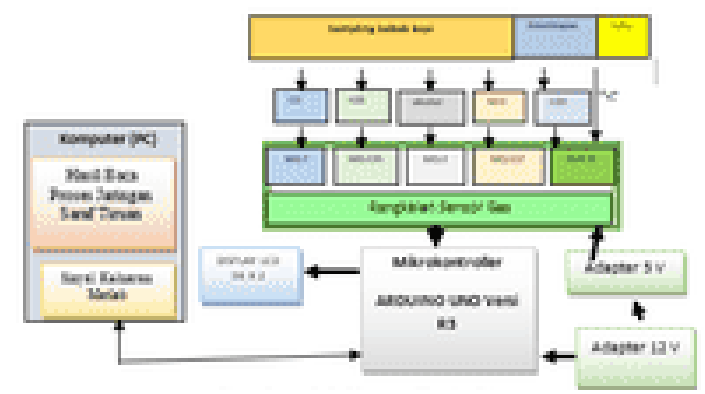

Gambar 2.1. Skema kerja sistem

\subsection{Pembuatan Hardware}

Pembuatan hardware dibagi menjadi dua; pertama merancang beberapa komponen elektrik yang dibutuhkan menjadi satu kesatuan rangkaian, kedua membuat mekanik alat yaitu: cover, base, dan box sampling.. Berikut gambaran dari alat yang sudah jadi

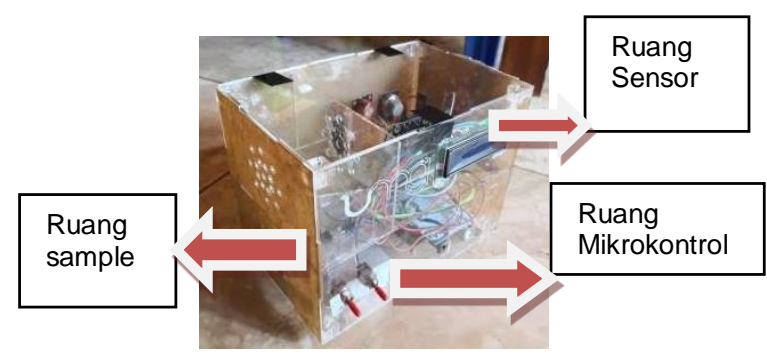

Gambar 2.2. Kotak sampling bubuk kopi

\section{Hasil Dan Pembahasan}

Pelatihan dilakukan dengan mengamati keluaran sinyal analog pada sensor gas secara beruruan dimana data ADC acak yang timbul dicatat pada setiap percobaan hingga mencapai data stabil. Dalam percobaan pengambilan data sampel diperoleh besaran nilai yang berbeda dari tiap sensor yang bergantung pada bubuk kopi yang diujikan. Setiap jenis bubuk kopi dilakukan 15 kali uji coba dan rata-rata waktu yang dibutuhkan mencapai posisi stabil tiap sampel adalah 10 hingga 15 menit. Sehingga di dapatkan pembacaan stabilisasi sensor yang akan dicatat pada MS.Excel dan diolah pada Matlab. Berikut contoh gambar grafik yang stabil pada gambar 3.1.

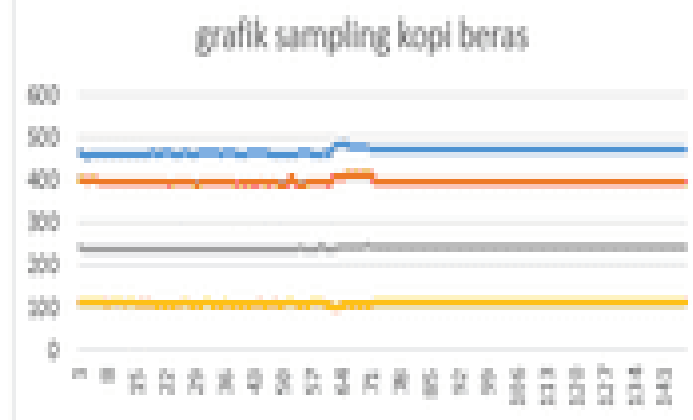

Gambar 3.1. Contoh Grafik Sampling

\subsection{Pengambilan data uji dan data latih Matlab}

Data output Delphi disimpan dan disusun berdasarkan percobaan yang sudah dilakukan. Gambar 3.2 dan Gambar 3.3

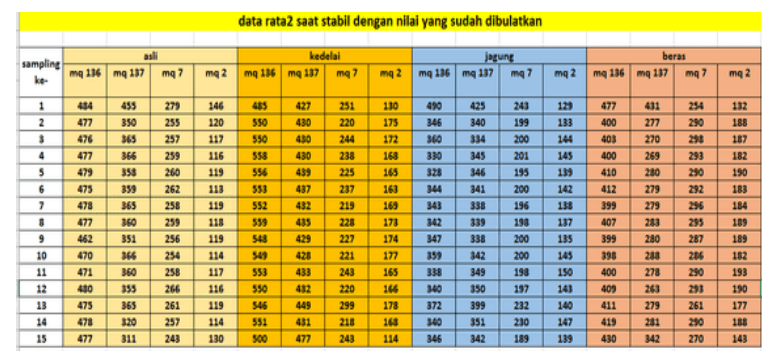

Gambar 3.2. Data rata-rata stabil bubuk kopi dengan perbandingan 10:30 dan 30:10

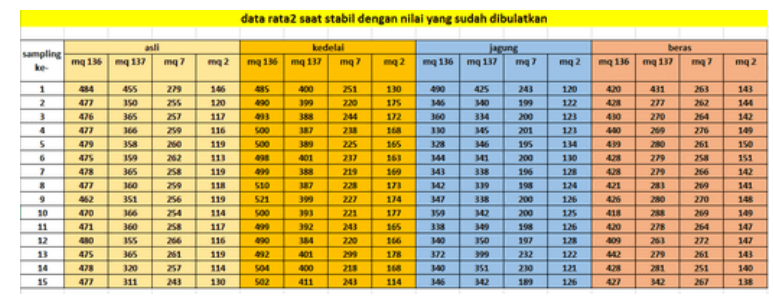

Gambar 3.3. Data rata-rata stabil bubuk kopi dengan perbandingan 30:10

Lalu pilih secara acak data tersebut untuk dijadikan data latih dan data uji seperti pada gambar 3.4. dan 3.5. 
Volume 15 Nomor 2 (2020) 11-15

E-Link P-ISSN 1858-2109 E-ISSN 2656-5676

Jurnal Teknik Elektro dan Informatika

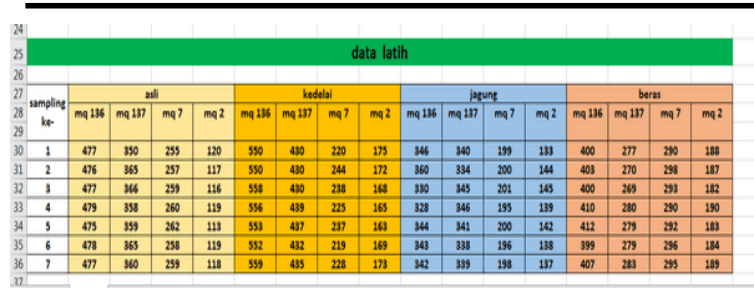

Gambar 3.4. Data latih bubuk kopi dengan perbandingan 10:30

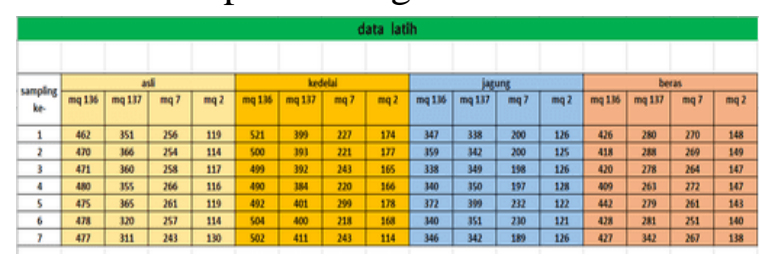

Gambar 3.5. Data latih bubuk kopi dengan perbandingan 30:10

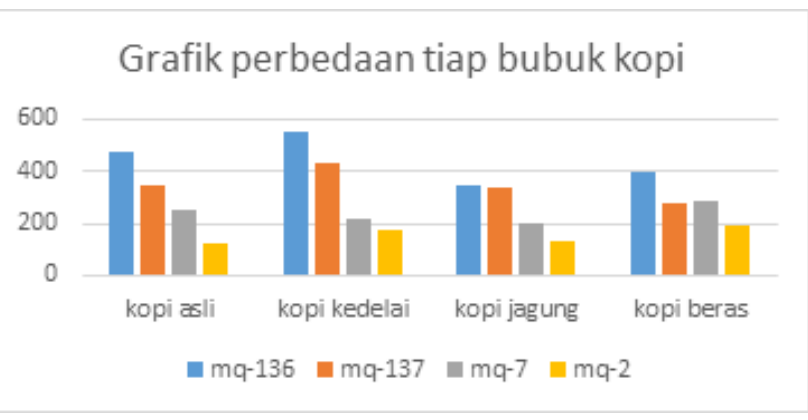

Gambar 3.6. Grafik perbedaan tiap bubuk kopi pada data latih bubuk kopi perbandingan 10:30

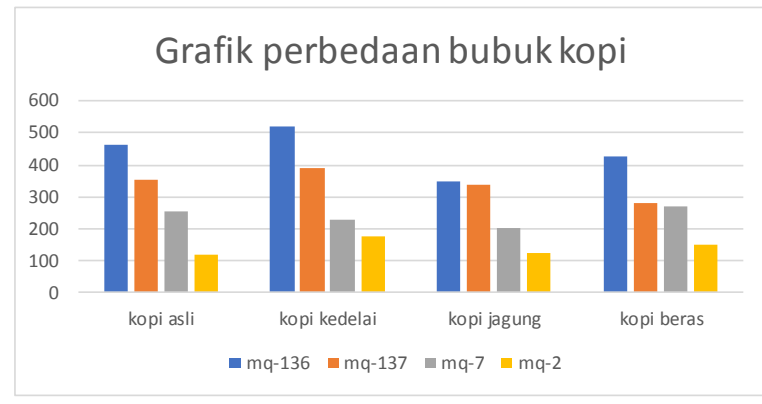

Gambar 3.7. Grafik perbedaan tiap bubuk kopi pada data latih bubuk kopi perbandingan 30:10

Terlihat dari grafik diatas ada perbedaan pada hasil sampling kopi kedelai dan kopi beras. Lalu pilih data uji berdasarkan tabel data stabil sebagai data yang akan dipakai pada Matlab. Berikut data uji perbandingan kopi 10:30 pada gambar 3.8.

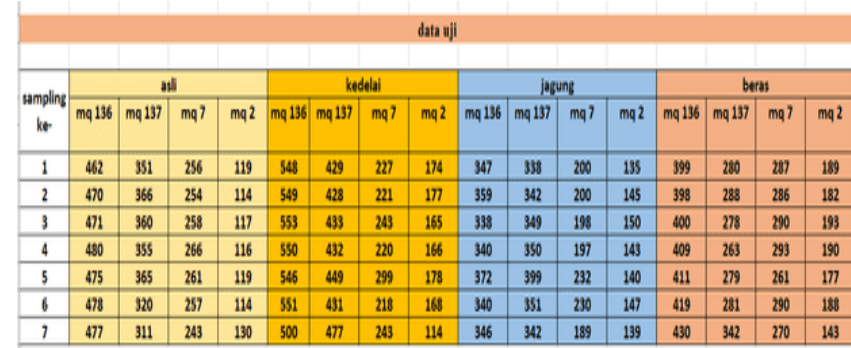

Gambar 3.8. Data uji bubuk kopi perbandingan 10:30

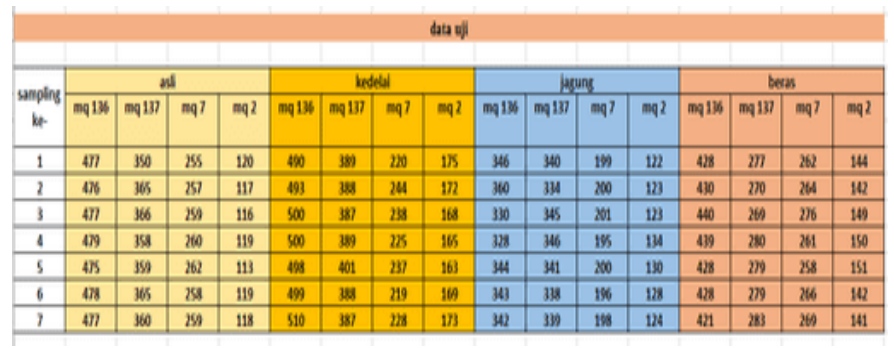

Gambar 3.9. Data uji pada perbandingan kopi 30:10

dan data uji bubuk kopi dengan perbandingan 30:10 pada gambar 3.9.

Setelah data latih dan data uji didapat maka, langkah selanjutnya adalah memasukkan data latih ke dalam kodingan Matlab dan jalankan program tersebut dengan penyesuaian parameter Matlab hingga sesuai harapan yaitu berhasil menunjukkan setiap kelas dari jenis bubuk kopi.

\subsection{Pengujian dan Penentuan Kelas}

Dalam pengujian dan penentuan kelas dilakukan pemasukkan data latih dari tiap bubuk kopi pada program LVQ Matlab. Dalam penelitian ini telah dilakukan beberapa kali percobaan penggantian hidden layer yang dipakai dengan nilai inputan data uji dan epoch yang tetap dalam rumusan Matlab. Berikut contoh proses pencarian hidden layer.

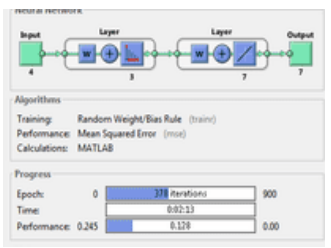

Gambar 3.10 Hidden layer 
Volume 15 Nomor 2 (2020) 11-15

E-Link P-ISSN 1858-2109 E-ISSN 2656-5676

Jurnal Teknik Elektro dan Informatika

Proses tersebut dilakukan terus menerus hingga menemukan jumlah hidden layer yang sesuai. Gambar 3.11 menunjukkan hasil uji coba pencarian nilai hidden layer

\begin{tabular}{|c|c|c|c|c|c|c|}
\hline $\begin{array}{l}\text { input } \\
\text { kelas }\end{array}$ & $\begin{array}{l}\text { hidsen } \\
\text { lesper }\end{array}$ & iterasil & time & performance & $\begin{array}{l}\text { hasit } \\
\text { helas }\end{array}$ & keterangan \\
\hline 5 & 1 & 700 & 0,005002 & 0.143 & 2 & tidak sesuai \\
\hline 5 & 3 & 254 & $0: 00: 13$ & 0.128 & 1 & tidsk sesuai \\
\hline 3 & 4 & 242 & $0,01: 28$ & 0.0962 & 1 & Eidak sesuai \\
\hline 5 & 6 & 417 & $0,02,32$ & 0.0437 & 3 & tisak sesuai \\
\hline 5 & 7 & 900 & $0,00 \times 21$ & 0.043 & 4 & tidak sesuai \\
\hline 5 & 59 & 25 & $0: 00: 14$ & 0 & 5 & sesuai \\
\hline
\end{tabular}

Gambar 3.11 data percobaan pencarian hidden layer

Data gambar 3.11, penggunaan hidden layer 59 pada bagian performance menunjukkan nilai mendekati 0 atau $<0,375$ bisa diterapkan pada data uji yang lain. Gambar 3.12 menunjukkan contoh tampilan proses Matlab menggunakan hidden layer 59 yang sesuai kriteria pada gambar 3.12.

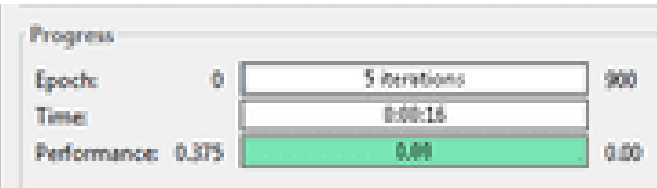

Gambar 3.12. Contoh performance yang sudah sesuai kriteria pada hidden layer 59 .

\subsection{Pengujian Keseluruhan}

Tahap selanjutnya adalah melakukan pengujian terhadap sistem identifikasi bubuk kopi oleh sensor gas dengan berbagai jenis sampel yang ada yang dicatat pada MS.Excel untuk mencari dan memilih data saat grafik stabil. Setelah data didapat kemudian dijadikan menjadi data latih dan data uji pada penulisan program Matlab. Berikut adalah hasil dari tes seluruh data uji ditunjukkan oleh tabel 3.1. menunjukkan hasil tes dari keseluruhan data uji pada bubuk kopi perbandingan 10:30 dan 30:10.

Tabel 3.1. Pengujian data uji bubuk kopi perbandingan 10:30 dan 30:10 dengan hidden layer 59
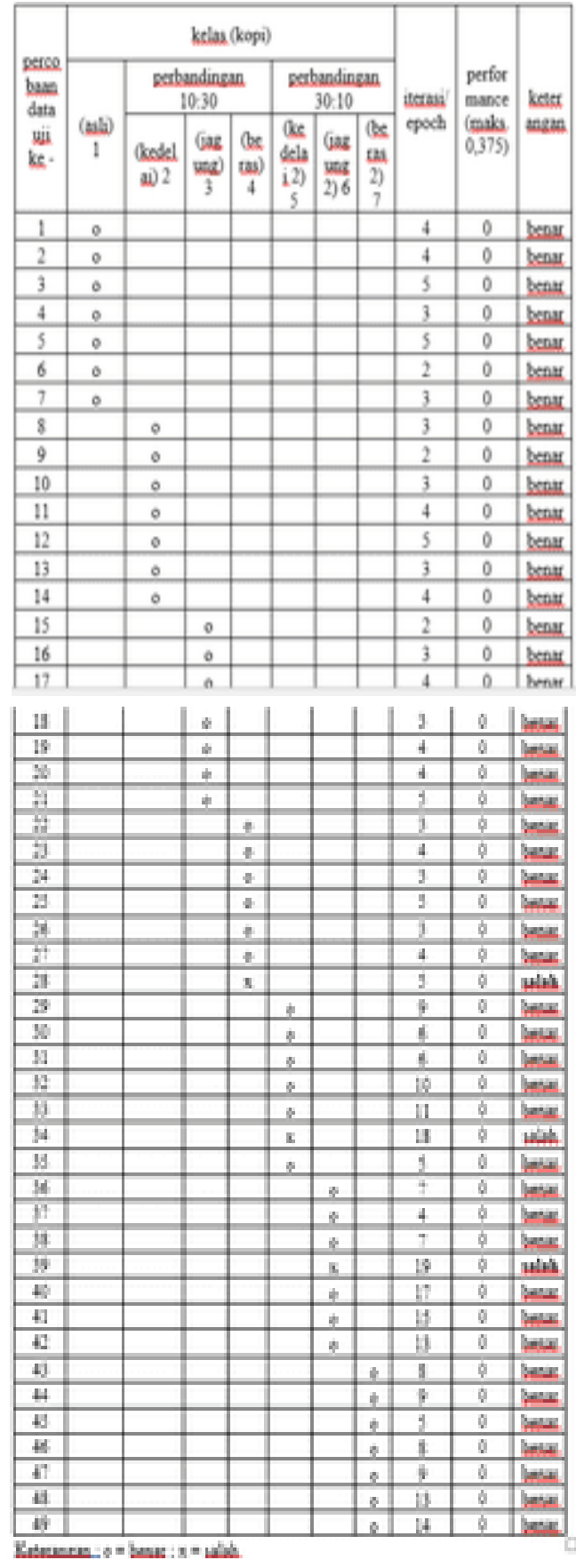

Berdasarkan data percobaan tersebut diperoleh nilai benar keseluruhan adalah 47 nilai dari total 49 kali percobaan maka untuk mengetahui tingkat akurasi ketepatan jaringan syaraf tiruan LVQ, bisa dihitung dengn cara (data uji benar/jumlah data uji keseluruhan) x $100 \%$. Nilai akurasi JST yang diharapkan adalah > 85\%. Berikut perhitungan akurasi diatas : 
( nilai benar / jumlah data uji ) x $100 \%=(47$ / 49 ) x $100 \%=95,92 \%$ ( sesuai harapan $>85 \%$ ) dengan tingkat errornya adalah $100 \%-95,92 \%=4,08 \%$.

\section{KESIMPULAN}

Berdasarkan hasil penelitian yang dilakukan dapat diambil kesimpulan bahwa pengunaan rangkaian sensor semikonduktor dapat meningkatkan kehandalan dari sistem karena memiliki selektifitas yang lebih banyak. Waktu yang dibutuhkan alat ini untuk proses sampling berkisar 10 hingga 15 menit. Metode learning vector quantization terbukti dapat digunakan untuk mengidentifikasi jenis bubuk kopi antara kopi asli, kopi jagung, kopi kedelai dan kopi beras dengan percobaan sebanyak 15 kali masingmasing sampel menghasilkan tingkat keakuratan 95,92\% dan tingkat eror 4,08\%.

\section{DAFTAR PUSTAKA}

[1] Adam Faroqi. 2017. Perancangan Alat Pendeteksi Kadar Polusi Udara Menggunakan Sensor Gas MQ-7 Dengan Teknologi Wireless HC-05. Jurnal Volume 3 No.X. Bandung : Fakultas Sains Dan Teknologi, Teknik Elektro. Universitas Teknologi Bandung.

[2] Andriansayah, Fendi, Misbah, P.S.S., Pressa, 2018. Sistem Monitoring Debu Dan Karbon Monoksida Pada Lingkungan Kerja Boiler Di PT. Karunia Alam Segar. Jurnal IKRA-ITH Teknologi Volume 2 Nomor 3. IKRA-ITH.

[3] Clarke, R.J., R.Macrae. 1985. Coffee Volume I : Chemistry. Elsevier Applied. Science Publishers, London.

[4] Fausett, L., 1994, Fundamentals of Neural Network: Architectures, Algorithms, and Applications, PrenticeHall,Inc.,New Jersey.

[5] Figaro. 2004, "General Information for TGS Sensor”, figarosensor.com

[6] Hanwei Electronics Co ., Ltd .Technical Data MQ-2 Gas Sensor. http://www.hwsensor.com
[7] Hanwei Electronics Co ., Ltd .Technical Data MQ-136 Gas Sensor. http://www.hwsensor.com

[8] Hanwei Electronics Co ., Ltd .Technical Data MQ-137 Gas Sensor. http://www.hwsensor.com

[9] Hari Santoso, 2017, Buku Monster Arduino, Belajar Konsep Dasar Arduino Volume 3, Bab (1-4), Jakarta : Elang Sakti [10] Kusumadewi, S.,2003. Artificial Intellegence (Teknik dan Aplikasinya), Graha Ilmu, Yogyakarta.

[11] Najiyati, S. Danarti, 1997. Budidaya Kopi dan Pengolahan Pasca Panen. Penebar Swadaya, Jakarta.

[12] Rabersyah, Desti, Firdaus, Derisma, 2016. Identifikasi Jenis Bubuk Kopi Menggunakan Electronic Nose Dengan Metode Pembelajaraan Backpropagation. Volume 5 Nomor 3. Jurnal Nasional Teknik Elektro.

[13] Rahardjo, Pudji. 2012. Panduan Budidaya dan Pengolahan Kopi Arabika dan Robusta. Penebar Swadaya. Jakarta.

[14] Siswoputranto, P.S., 1992. Kopi Internasional dan Indonesia. Kanisius, Yogyakarta.

[15] Spillane,J.J., 1990. Komoditi Kopi Peranannya Dalam Perekonomian Indonesia. Kanisius, Yogyakarta 